\title{
THE SHEAR BOND STRENGTH OF THE AESTHETIC BRACKETS BY USING SELF ETCHING PRIMERS
}

\author{
Mohamed Ahmed Salem*
}

\begin{abstract}
Background: Aesthetic brackets have considerably less mechanical undercuts than those on a metal mesh base design, and therefore they might be expected to have a greater bond failure rate if they are used without a silane-coupling agent.
\end{abstract}

Aim: This study was designed to evaluate the effect of using Self etching on the shear bond strength of the Aesthetic brackets.

Material and methods: This study was carried out on fivety premolar teeth were collected from orthodontic patients attending out-patient orthodontic clinic, faculty of Dental Medicine, Al-Azhar University who will be treated with premolar extraction. The teeth were cleaned with tap-water, brushed and stored in distilled water with $0.1 \%$ thymol until use. The collected teeth were divided into two groups, one of them was used in dry condition and the other was used in contaminated condition. Each group was sub divided into two equal subgroups of teeth with uncoated and pre coated ceramic bracket for testing the shear. Descriptive statistics including the mean; standard deviation; minimum and maximum values for the Shear bond strength (SBS) were calculated for each of the 10 test groups. The results of this study showed that New metal-reinforced orthodontic ceramic brackets (Clarity brackets) presented a clinically acceptable shear bond strength value with Transbond Moisture-insensitive primer and Transbond Plus-self etching primer can be used successfully for bonding clarity ceramic brackets (uncoated and pre coated) under dry and salivary contaminated condition.

Conclusion: Pre coated ceramic brackets in contaminated condition presented higher self etching primer than uncoated ceramic brackets.

\section{INTRODUCTION}

Ceramic brackets were introduced in the 1980's, offering many advantages over the traditional aesthetic appliances ${ }^{(1)}$. It provided higher strength, more resistance to wear and deformation, better color stability and, most important to the patient, superior aesthetics ${ }^{(2)}$. The introduction of the acid etch bonding technique has led to dramatic change in practice of orthodontics ${ }^{(3,4,5)}$. Ceramic brackets have several disadvantages: ${ }^{(6,7)}$ The inability to form chemical bonds with the available adhesives

* DDS, Lecture in Orthodontic, Al-Azhar University, Faculty of Dentistry, Assuit, Egypt 
without the use of a coupling agent ${ }^{(8)}$. Consequently, the early ceramic brackets used a silane coupler to act as a chemical mediator between the base and the adhesive $\mathrm{e}^{(9,10)}$. This resulted in an extremely strong bond that may cause the enamel-adhesive interface to be stressed during debondiog increasing the risk of tooth damage $(11,12,13)$. There are three mechanisms by which a ceramic bracket adheres to the adhesive: (a) chemical, (b) mechanical and (c) a combination of both ${ }^{(14)}$. Laboratory testing of mechanical retention indicates that adhesive to bracket bond strength of ceramic brackets is lower than those of equivalent sized foil mesh metallic brackets $^{(15)}$. Ceramic brackets have considerably less mechanical undercuts than those on a metal mesh base design, and therefore they might be expected to have a greater bond failure rate if they are used without a silane-coupling agent ${ }^{(16,17)}$. The increased adhesion produced by acid pretreatment, using $85 \%$ was used ${ }^{(18,19,20)}$.

\section{AIM}

This study was designed to evaluate the effect of using Self etching on the shear bond strength of the Aesthetic brackets.

\section{MATERIAL AND METHODS}

Fivety extracted premolar teeth were taken from orthodontic patients attending out-patient orthodontic clinic, faculty of Dental Medicine, AlAzhar University after being treated by premolar extraction. The teeth had macroscopically sound buccal and lingual surfaces, free from caries, cracks, white spots, or anomalies as hypoplasia, and hypo calcification. They were not previously treated by chemicals as hydrogen peroxide or alcohol. The teeth were cleaned with tap water, brushed, and stored in distilled water with $0.1 \%$ thymol until use.

\section{Brackets}

Seventy Clarity ${ }^{\mathrm{TM}}$ Metal-Reinforced Ceramic Brackets (Clarity, 3M Unitek , Monrovia, Calif, uncoated and precoated) for direct bonding of first premolar teeth were chosen. Clarity ceramic brackets are polycrystalline ceramic brackets, feature micro crystalline bonding surface provides the consistency, strength and reliability of mechanical retention on the bonding base. Mechanical lock base provides reliable bond strength with all chemical and light cure-bonding systems no special primers or pretreatments are necessary. Uncoated Clarity Metal-Reinforced Ceramic Brackets. Precoated ceramic brackets with APC тм PLUS adhesive coating have a pink color of the adhesive. This pink color fades to clear when exposed to light curing. This allows for better flash clean up and more predictable deboning. Starting in the pink may also improve the visual reference of the bracket, which can help make positioning easier and more accurate, according to the manufacturer the average base surface area of each was $12 \mathrm{~mm}^{2}$. The Transbond XT adhesive (light-cured composite resin) was used for bonding un-coated Ceramic bracket.

\section{Primers}

Three types of orthodontic primers were used in this study. The Transbond XT (3M Unitek, Monrovia, Calif) conventional primer is used as a control, and it is a hydrophobic Bis-GMA based, light cured primer. The Moisture-insensitive primer (3M Unitek, Monrovia, Calif) was originally developed as a hydrophilic primer belonging to the fifth generation of dentin bonding agents. Moisture insensitive primer consists of an aqueous solution of methacrylate-functionalized polyalkenoic acid co-polymer and hydroxyethyl-methacrylate. The Transbond Plus Self-etching primer (3M Unitek, Monrovia, Calif) is marketed as tolerable to moisture with the additional advantage of combining the etchant with the primer thus requiring no surface conditioning prior to its application. Trans bond Plus Self-etching primer is supplied in a lollipopshaped aluminum foil packet that consists of three separated compartments. The ingredients are mixed 
and activated by pressure prior to use. The first chamber contains methacrylated phosphoric acid esters, photo initiators and stabilizers; the second chamber contains water, fluoride complex, and additional stabilizers. Ingredients are mixed after the first compartment is popped and folded over the second, then both are popped into the third. In the third chamber, a micro brush applicator is used to rub the mixture over the enamel of each tooth for a three seconds then an oil-moisture free air source is used to deliver a gentle air burst for 2 seconds on each tooth surface. Self-etching primer is light cured together with the adhesive after the bracket bonding.

\section{Strength testing machine}

Universal testing machine (Lloyed Universal testing machine, made in $U K)$ at the dental biomaterials department, Faculty of dental medicine, Al-Azhar University, was used for evaluation of shear bond strength of the brackets in each groups.

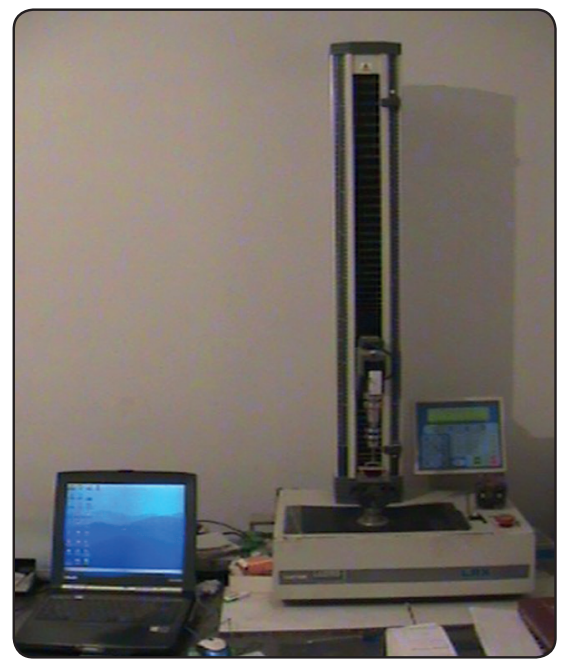

Fig. (1) Strength testing machine

\section{Preparation of the specimen ${ }^{(21)}$}

\section{Direct bonding procedure}

Fivety teeth randomly divided into two groups, one of them was used in dry condition, and the other was used in contaminated condition. Each group was sub divided into two equal subgroups of teeth with uncoated and pre coated ceramic bracket for testing the shear bond strength.

\section{1) Polishing}

Before bonding, the buccal surface of each tooth was polished with a non-fluoridated, oil-free, pumice paste using a rubber prophylactic cup on a low-speed hand piece for 10 seconds. The enamel surface was then thoroughly rinsed, and dried with oil-free, air-water spray.

\section{2) Conditioning and priming}

In groups utilizing conventional primer and moisture insensitive primer the teeth were etched using 37\% phosphoric acid for 15 seconds as surface conditioning then rinsed for 10 second and dried with oil-moisture free air source for 10 seconds. In groups utilizing Transbond plus Selfetching primer require no conditioner prior to its application, as the self etching primer etches and primes simultaneously. In groups designated for salivary contamination, a thin coat of fresh human saliva was applied with a brush to the labial surfaces. The saliva was collected from one donor, who was instructed to brush his teeth and not to eat for one hour before the saliva was collected

\section{Priming}

Fivety teeth were randomly divided into 10 groups, 5 teeth each according to the following ten protocols. Group (A) Teeth in dry condition: (1) Uncoated ceramic bracket with conventional primer. Etching using 37\% phosphoric acid, then a thin coat of conventional primer was applied to the dry enamel surface (Control group 1). (2) Uncoated ceramic bracket with moisture insensitive primer. Etching using 37\% phosphoric acid, then a thin coat of moisture insensitive primer was applied to the dry enamel surface. (3) Uncoated ceramic bracket with self- etching primer. A thin coat of selfetching primer will be applied to the dry enamel surface.The same steps were used with Pre coated 
ceramic bracket. (4) Pre coated ceramic bracket with conventional primer (Control group 2). (5) Pre coated ceramic bracket with moisture insensitive primer. (6) Pre coated ceramic bracket with selfetching primer. Group (B) Teeth in contaminated condition: (7) Uncoated ceramic bracket with moisture insensitive primer. Etching using 37\% phosphoric acid, then a thin coat of human saliva was applied to the enamel surface then moisture insensitive primer was applied. (8) Uncoated ceramic bracket with Self-etching primer. A thin coat of human saliva was applied to the enamel surface then Self-etching primer was applied to the enamel surface. The same steps were used with Pre coated ceramic bracket. (9) Pre coated ceramic bracket with moisture insensitive primer. (10) Pre coated ceramic bracket with Self- etching primer.

\section{3) Bonding}

A thin layer of the Transbond XT adhesive lightcured composite was applied to the undersurface of the un-coated ceramic brackets base which was placed on the enamel surface in a sliding motion, occlusal to gingival, forcing excess adhesive to the incisal edge of the bracket for easier clean-up, and kept under firm pressure for 10 seconds. A dental probe was used to remove the excess resin from the bracket base periphery after the bracket was placed. Precoated brackets with APC ${ }^{\mathrm{TM}}$ PLUS Adhesive coating on each bracket, needs no adhesive mixing or application.

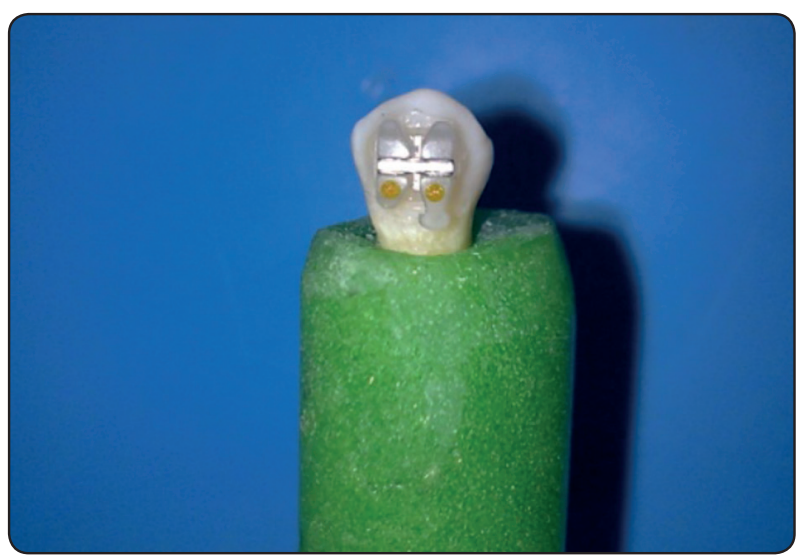

Specimen in acrylic model

\section{4) Light curing}

The DEMI _ LED light curing unit was used with light intensity of $\geq 950 \mathrm{~m} \mathrm{~W} / \mathrm{cm}$ and wavelength range of 370-500 $\mathrm{nm}$ Each bracket was light cured for 20 seconds.

\section{Mounting of the bonded teeth in acrylic by using metal rings}

Metal rings were filled by self-cured resin and the specimens were adjusted so that the labial surface of the teeth was perpendicular to the true horizontal using standardized method for all specimens. Care was taken to prevent brackets from touching the acrylic resin. When the acrylic resin had set, the mounted teeth were removed from the rings.

\section{Bond strength determination by using Universal testing machine}

The machine was used to determine the amount of force applied to de-bond the brackets and then divided by the surface area of the bracket to obtain the desired strength. Each sample was mounted on the lower fixed compartment of a computer controlled materials testing machine (Model LRX-plus; Lloyd Instruments Ltd., Fareham, UK) with a load cell of $5 \mathrm{kN}$ and data were recorded using computer software (Nexygen-4.1; Lloyd Instruments), Then subjected to a shearing force by compressive mode in occluso gingival direction at a crosshead speed of $0.5 \mathrm{~mm} / \mathrm{min}$ via chisel edge

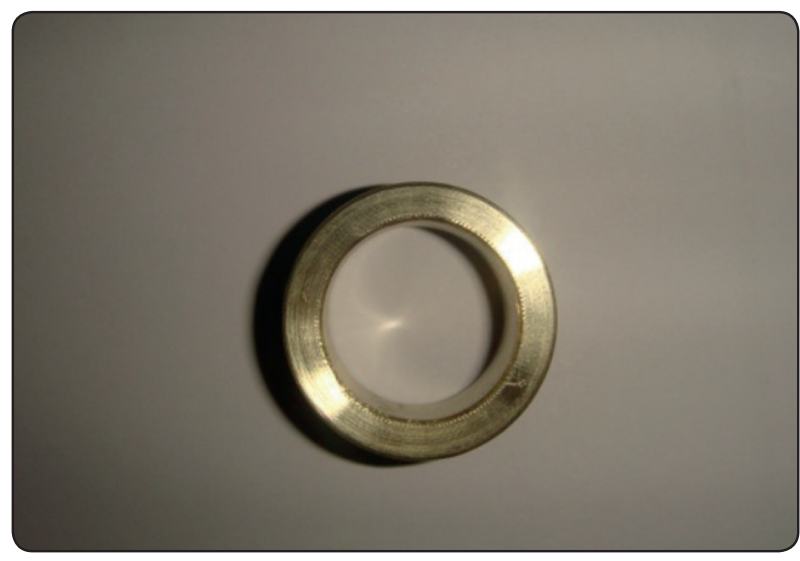

Metal ring 


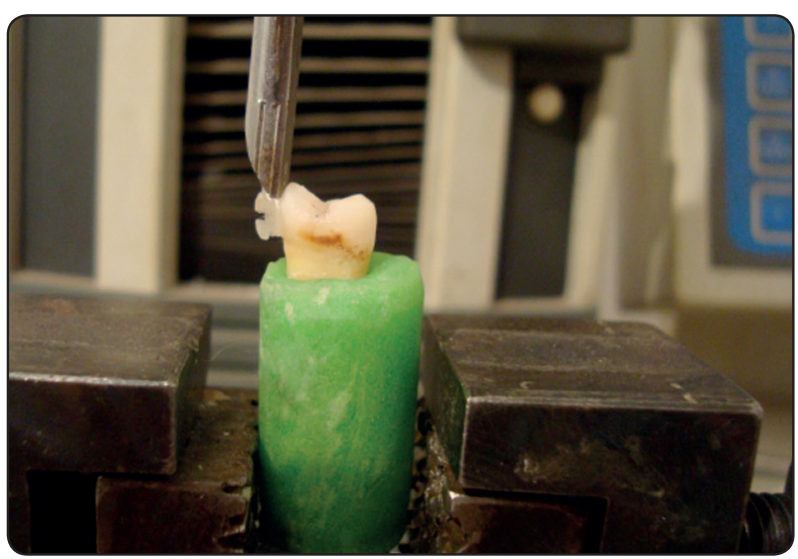

rod attached to the upper movable compartment of testing machine. The chisel tip positioned to touch only the base of the bracket. The maximum failure load was recorded in $\mathrm{N}$.

\section{RESULTS}

Descriptive statistics including the mean; standard deviation; minimum and maximum values for the SBS were calculated for each of the 10 test groups. The one way analysis of variance (ANOVA test) was used to determine whether significant differences were present in the SBS between the 10 groups. (Tukey HSD) were used to determine which means were significantly different from each other. Significance for the statistical tests was predetermined at $(\mathrm{P}<0.05)$.

\begin{tabular}{|c|c|c|c|}
\hline Groups & $\begin{array}{c}\text { Number of } \\
\text { values }\end{array}$ & Mean & Std. Deviation \\
\hline Gr1 & 5 & 22.46 & 5.933 \\
\hline Gr2 & 5 & 18.49 & 6.773 \\
\hline Gr3 & 5 & 11.91 & 2.712 \\
\hline Gr4 & 5 & 15.37 & 3.519 \\
\hline Gr5 & 5 & 17.85 & 4.889 \\
\hline Gr6 & 5 & 17.56 & 5.784 \\
\hline Gr7 & 5 & 14.29 & 4.745 \\
\hline Gr8 & 5 & 12.79 & 4.476 \\
\hline Gr9 & 5 & 16.83 & 8.430 \\
\hline Gr10 & 5 & 17.58 & 5.829 \\
\hline
\end{tabular}

The results of the one way analysis of variance (ANOVA test) $(\mathrm{F}=2.153262)$ indicated that there were no statistically significant differences $(\mathrm{P}=0$. $38359>0.05$ ) between any of the 10 groups.

\begin{tabular}{|c|c|c|c|c|c|}
\hline $\begin{array}{c}\text { Source of } \\
\text { Variation }\end{array}$ & $\begin{array}{c}\text { Sum of } \\
\text { Squares }\end{array}$ & $\begin{array}{c}\text { Degree of } \\
\text { freedom }\end{array}$ & $\begin{array}{c}\text { Mean } \\
\text { sum of } \\
\text { squares }\end{array}$ & F ratio & P-value \\
\hline $\begin{array}{c}\text { Between } \\
\text { Groups }\end{array}$ & 592.5793 & 9 & 65.84214 & 2.153262 & 0.38359 \\
\hline $\begin{array}{c}\text { Within } \\
\text { Groups }\end{array}$ & 1834.672 & 60 & 30.57786 & & \\
\hline Total & 2427.251 & 69 & & & \\
\hline
\end{tabular}

NOVA test for comparison of shear bond strengths of different test groups. (5\% Level of significance)

The results of the one way analysis of variance (ANOVA test) ( $\mathrm{F}=6.737$ ) indicated that there were no statistically significant differences $(\mathrm{P}=0.1169>$ 0.05 ) between any of the first three groups evaluated (un coated brackets with conventional, MIP, SEP in dry condition).According to the one way analysis of variance ANOVA test there were no statistically significant differences $(\mathrm{P}=0.38359>0.05)$ between any of the 10 groups evaluated there were no statistically significant differences $(\mathrm{P}=0.5145>0.05)$ between any of the second three groups evaluated (pre coated brackets with conventional ,MIP and SEP in dry condition).

\begin{tabular}{|c|c|c|c|c|c|}
\hline $\begin{array}{c}\text { Source of } \\
\text { Variation }\end{array}$ & $\begin{array}{c}\text { Sum of } \\
\text { Squares }\end{array}$ & $\begin{array}{c}\text { Degree of } \\
\text { freedom }\end{array}$ & $\begin{array}{c}\text { Mean sum } \\
\text { of squares }\end{array}$ & F ratio & P-value \\
\hline $\begin{array}{c}\text { Between } \\
\text { Groups }\end{array}$ & 397.2 & 2 & 198.6 & 6.737 & 0.1169 \\
\hline $\begin{array}{c}\text { Within } \\
\text { Groups }\end{array}$ & 530.6 & 18 & 29.48 & & \\
\hline Total & 927.8 & 20 & & & \\
\hline
\end{tabular}

ANOVA test for comparison of shear bond strengths of GR1,GR2,GR3. (5\% Level of significance) 
The results of the one way analysis of variance (ANOVA test) $(\mathrm{F}=0.5549)$ indicated that there were no statistically significant differences $(\mathrm{P}=0.5145>$ 0.05 ) between any of the second three groups evaluated (pre coated brackets with conventional, MIP and SEP in dry condition).

\begin{tabular}{|c|c|c|c|c|c|}
\hline $\begin{array}{c}\text { Source of } \\
\text { Variation }\end{array}$ & $\begin{array}{c}\text { Sum of } \\
\text { Squares }\end{array}$ & $\begin{array}{c}\text { Degree } \\
\text { of } \\
\text { freedom }\end{array}$ & $\begin{array}{c}\text { Mean } \\
\text { sum of } \\
\text { squares }\end{array}$ & F ratio & P-value \\
\hline $\begin{array}{c}\text { Between } \\
\text { Groups }\end{array}$ & 25.80 & 2 & 12.90 & 0.5549 & 0.5145 \\
\hline $\begin{array}{c}\text { Within } \\
\text { Groups }\end{array}$ & 418.5 & 18 & 23.25 & & \\
\hline Total & 444.3 & 20 & & & \\
\hline
\end{tabular}

ANOVA test for comparison of shear bond strengths of groups GR4, GR5, GR6 . (5\% Level of significance)

The results of the one-way analysis of variance (ANOVA test) $(\mathrm{F}=0.9378$.) indicated that there were no statistically significant differences $(\mathrm{P}=$ $0.3942>0.05)$ between the groups in contaminated condition (pre coated and uncoated brackets with, MIP and SEP in contaminated condition).

\begin{tabular}{|c|c|c|c|c|c|}
\hline $\begin{array}{c}\text { Source of } \\
\text { Variation }\end{array}$ & $\begin{array}{c}\text { Sum of } \\
\text { Squares }\end{array}$ & $\begin{array}{c}\text { Degree of } \\
\text { freedom }\end{array}$ & $\begin{array}{c}\text { Mean sum } \\
\text { of squares }\end{array}$ & F ratio & P-value \\
\hline $\begin{array}{c}\text { Between } \\
\text { Groups }\end{array}$ & 103.8 & 3 & 34.60 & 0.9378 & 0.3942 \\
\hline $\begin{array}{c}\text { Within } \\
\text { Groups }\end{array}$ & 885.6 & 24 & 36.90 & & \\
\hline Total & 989.4 & 27 & & & \\
\hline
\end{tabular}

ANOVA test for comparison of shear bond strengths of groups GR7, GR8 ,GR9, GR10 . (5\% Level of significance)

The Box plot shows distribution of the shear bond strength values for each of the test groups, where the box represents the inter quartile range which contains $50 \%$-of the values, the whiskers are lines that extend from the box to the highest and lowest values, and the line across the box indicates the median.

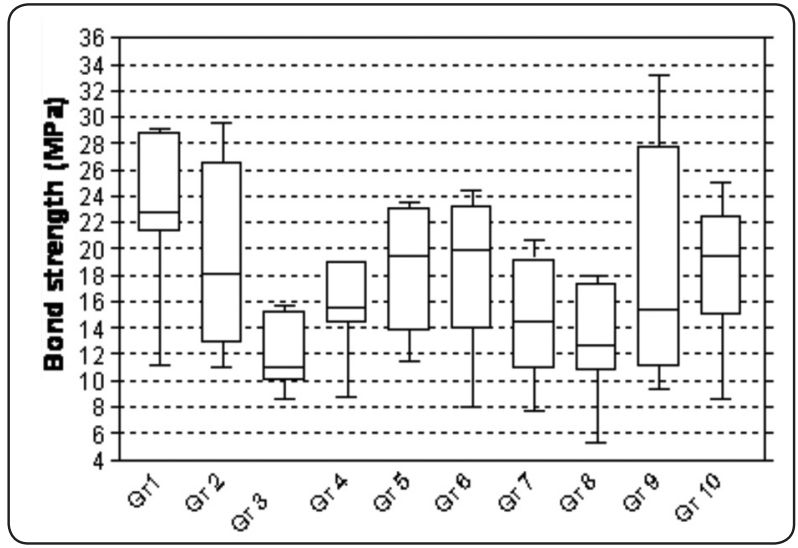

Both uncoated brackets with SEP in dry and contaminated condition (GR3), (GR8) showed a mean SBS $(11.91 \pm 2.712 \mathrm{MPa}),(12.79 \pm 4.476 \mathrm{MPa})$ respectively which was lower than all other groups. The differences were statistically significant with (GR1) uncoated brackets with conventional in dry condition. On the other hand, (GR3) was only statistically different with (GR2) uncoated brackets with MIP in dry condition, (GR5) pre coated brackets with MIP in dry condition and (GR6) pre coated brackets with SEP in dry condition. The differences were statistically significnt.

\section{DISCUSSION}

Currently, there are two types of ceramic bracket bases available. One type of bracket base is formed with undercuts or grooves that provide a mechanical interlock to the adhesive. The mechanical retention of such brackets is less as compared to other bracket base that are having both micro mechanical retention and chemical adhesion ${ }^{(1)}$. The other type of bracket base has a smooth surface and relies on a chemical coating to enhance bond strength. A silane coupling agent is used as a chemical mediator between the adhesive resin and the bracket base ${ }^{(2)}$. It has been claimed that chemical adhesion provided higher bond strength when compared with mechanical retention ${ }^{(3)}$. Recently, another two developments in ceramic bracket base technology has come that use polycrystalline alumina with a rough base comprised of either randomly oriented sharp crystals or 
spherical glass particles. These brackets provide only micromechanical interlocking with the orthodontic adhesive (1). The occurrence of the enamel fràctures is due to the high bond strength of ceramic brackets. The mean bond strength for the different bracket, adhesive and enamel conditioner combinations ranged from a minimum of 3.9MPa to maximum of $18.6 \mathrm{MPa}$. Minimum bond strength of $5.9 \mathrm{MPa}$ to $7.8 \mathrm{MPa}$ was found to be adequate for most clinical orthodontic needs ${ }^{(4)}$. However, most of the adhesives available on the market have bond strength between $5.9 \mathrm{MPa}$ to $11.3 \mathrm{MPa}$ and few studies reported maximum of $29.4 \mathrm{MPa}^{(7)}$. The shear bond strength of ceramic brackets was found to be more than stainless steel brackets ${ }^{(3)}$. Thus, when the force required to remove the bracket from the enamel exceeds the mean linear tensile strength of the enamel or the bracket itself, fracture of the enamel surface or the bracket takes place. Retief reported that enamel fracture can occur with bond strengths as low as $13.5 \mathrm{MPa}$ which was comparable to the linear tensile strength of the enamel ${ }^{(6)}$. Therefore, a debonding technique that reduces the required forces for de bracketing reduces the risk of enamel fracture. The different bond strength between mechanical and chemical bonding is due to the way stress concentration is distributed over the bonding surfaces. Ceramic brackets that offer a mechanical bond with the adhesive have retentive grooves in which edge angles are 90 degree $^{(7)}$. There are also crosscuts to prevent the brackets from sliding along the undercut grooves that have sharp edge angles, thus bond strength can be affected not only by the bracket base design, but also by various other factors such as type of bonding resin, etching time, condition, and preparation of teeth involved ${ }^{(8,9)}$. The introduction of the new metal reinforced ceramic brackets (Clarity brackets) was an attempt to decrease enamel damage during the debonding of the brackets. In present study, Clarity brackets had a mean bond strength value significantly higher with conventional primer ${ }^{(5)}$. On the other hand the mean bond strength was lower than the results of Joseph and Rossouw (9) who found higher mean bond strength values for ceramic brackets with mechanical retention. The present study differed from the previous studies in that we used two new bonding system SEP and MIP in dry and contaminated conditions. In this study the mean SBS for (GR3) un coated with the SEP in dry condition and (GR8) un coated with the SEP in contaminated condition, they had significantly lower SBS than all other groups. This was comparable to that reported by Mundstock $^{(5)}$, that Pre coated brackets with SEP in dry and contaminated conditions (GR6), (GR10) showed a mean SBS $(17.56 \pm 5.784 \mathrm{MPa}),(17.58 \pm$ $5.829 \mathrm{MPa}$ ) respectively which was comparable to that achieved with pre coated brackets with MIP in contaminated conditions (GR 9) (mean $16.83 \pm 8.430 \mathrm{MPa})$. This was higher than those

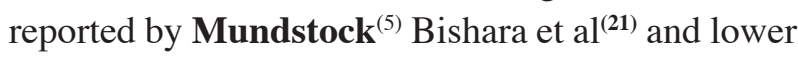
than those reported by Joseph and Rossouw (9) Moreover, in present study the lower SBS was reported with (GR4) pre coated Ceramic Brackets bonded with the conventional primer in dry condition. Although the enamel can often withstand greater forces, as indicated by large standard deviations in the debonding force levels reported, it is advisable to follow the instructions for debonding as recommended by the manufacturer to avoid damaging the enamel. Some new bonding systems in operative dentistry combine the conditioning and priming agents into a single acidic primer solution for simultaneous use on both enamel and dentin ${ }^{(11,13)}$. Contamination can compromise the retention of the appliances, mainly when a moisture-sensitive material is employed. Contrary to the hydrophobic features of conventional Transbond XT, the selfetch primer is hydrophilic and therefore this material can achieve high bond strength values even when the enamel is contaminated with saliva or water and another possible solution to this problem has been offered by the development of the moistureinsensitive primer (MIP). These were developed based on dentin-bonding agents, which have hydrophilic components, such as hydroxyl ethyl methacryla te and malic acid dissolved in acetone, that are efficient even in the presence of moisture ${ }^{(\mathbf{1 0})}$. 
In present study, the three types of primers (Transbond XT, Transbond MIP, and Transbond plus SEP) were evaluated. The results indicated that the shear bond strengths test showed no statistically difference in the mean shear bond strengths of the ten tested groups. The results in this study indicated that the highest shear bond strengths obtained when (Transbond XT) was used in a dry field (GR1), followed by (Transbond MIP) in a dry field (GR2) and they had significantly higher mean SBS than (GR3) SEP in a dry field $(11.91 \pm 2.712 \mathrm{MPa}$. This finding agreed with Zeppieri ${ }^{(\mathbf{2 0})}$ who found that under dry conditions, Transbond XT and MIP produced a significantly higher mean SBS compared to SEP, and did not agree Cacciatesta et al, and Rajagopal ${ }^{(15)}$ who found no significant difference in shear bond strengths of the three primers under dry conditions. In (GR4) pre coated with (Transbond XT) in dry condition lower than (GR5) pre coated with MIP in dry condition but there was no statistically significant difference between the two groups. This finding agreed with Webster ${ }^{(19)}$ as they found was no statistically significant difference between Transbond XT primer and Transbond MIP in a dry environment. However, was in direct contrast to the findings of Littlewood ${ }^{(12)}$ in which the bond strengths of adhesive used with Transbond MIP were significantly lower than those with Transbond XT primer under dry conditions. In this result the both uncoated brackets with SEP in dry and contaminated condition (GR3), (GR8) showed a mean SBS $(11.91 \pm 2.712 \mathrm{MPa}),(12.79 \pm 4.476 \mathrm{MPa})$ respectively which was lower than all other groups. The differences between the two groups (GR3) and (GR8) were statistically non significant indicated that the SBS of SEP not affected by the salivary contaminated condition. Precoated brackets with Self-Etching Primer (SEP) in dry and in contaminated condition (GR6) and (GR10) showed a higher SBS and the differences were statistically non significant between the two groups indicated also that the SBS of SEP not affected by the salivary contaminated condition. As seen in this study it was agreed with my many authors Zeppieriand Mante, Rajgobal, and Gnanamani ${ }^{(20)}$ who found that saliva has no effect on the SBS of SEP. This finding in contrast with Bishara ${ }^{(14)}$ who stated that there was a $25 \%$ reduction in SBS when saliva was present. Un coated Ceramic Brackets with SEP had SBS significantly lower than Transbond XT and Transbond Moisture In Sensitive Primer (MIP) that agreed with Bishara ${ }^{(5)}$ Who found that Transbond XT had significantly higher SBS than the SEP. However, there were contradicting with the previous results revealed that the SBS of SEP in dry and in contaminated condition were comparable with the SBS of Transbond XT and MIP in pre coated brackets with SEP in dry and in contaminated condition. A possible explanation of the differences in bond strength recorded in this study and other studies is the variation in the testing condition. Some studies used bovine teeth instead of human teeth ${ }^{(17)}$, Others used different storage media as formalin which was reported as a possible cause of increased enamel, fractures, leading to changes in the bond strength values ${ }^{(18)}$, Others used thermocycling before the shear bond strength test. In addition, might be the result of variability in proper fit between the bracket base and the premolar crown due to unavoidable anatomic variability ${ }^{(20)}$. The operator's inability to position the testing machine's blade precisely might account for the wide variation. Some studies have reported the use of a wire loop around the bracket to connect it to the machine to measure shear-peel bond strength. This approach has not reduced variability in the data. Thus, a wide range might be considered an inherent finding when in vitro shear bond strength studies are conducted ${ }^{(20)}$. Clinicians should remember that this was an in vitro study and the results are not necessarily the same as those that would be obtained in the oral environment. The clinician has to decide whether the time and steps saved during the bonding procedure as well as decreasing the chances of contamination balances the increased cost incurred when using the new bonding system. 


\section{CONCLUSION}

Pre coated ceramic brackets in contaminated condition presented higher self etching primer than uncoated ceramic brackets. Teeth with uncoated and pre coated ceramic bracket for testing the shear. New metal-reinforced orthodontic ceramic brackets (Clarity brackets) presented a clinically acceptable shear bond strength value with Transbond MIP and Transbond Plus -SEP above the minimal force levels suggested by Reynolds for a successful clinical bonding (5.9 to7.8 MPa).

\section{REFERENCES}

1- Eliades T, Lekka M, Eliades G, Brantley WA. Surface characterization of ceramic brackets: a multitechnique approach. Am J Orthod Dentofac Orthop 1994; 105: 10-18.

2- Swartz ML. A technical bulletin on the issue of bonding and debonding ceramic brackets. Glendora (CA): Ormco Corp1988; 070-5039.

3- Viazis AD, Cavanaugh G, Bevis RR. Bond strength of ceramic brackets under shear stress: an in vitro report. Am J Orthod Dentofac Orthop 1990; 98: 214-221.

4- Reynolds IR. A review of direct orthodontic bonding. Br J Orthod 1979; 2: 171-178.

5- Mundstock, K S. Sadowsky L, Lacefield W and Bae, S. An in vitro evaluation of a metal reinforced orthodontic ceramic bracket(Am J Orthod Dentofacial Orthop 1999;116:635-41).

6- Retief DH. Failure at the dental adhesive-etched enamel interface. J Oral Rehabil 1974; 1: 265-284.

7- Odegaard J, Segner D. Shear bond strength of metal brackets compared with a new ceramic bracket. Am J Orthod Dentofac Orthop 1988; 94: 201-206.

8- Ghafari J, Skanchy TL, Mante F. Shear bond strengths of two ceramic brackets. J Clin Orthod 1992; 26: 491-493.

9- Joseph VP, Rossouw E. The shear bond strengths of stainless steel and ceramic brackets used with chemically and light-activated composite resins. Am J Orthod Dentofac Orthop 1990; 97: 121-125.

10- Triolo PT Jr, Swift EJ Jr, Mudgil A, Levine A. Effects of etching time on enamel bond strengths. Am J Dent 1993; 6:302-304.

11- Chigira H, Koike T, Hasegawa T, Itoh K, Wakumoto S, Hyakawa T. Effect of the self-etching dentin primers on the bonding efficacy of dentine adhesive. Dent Mater J. $1989 ; 8: 86-92$.

12- Littlewood SJ, Mitchell L, Greenwood DC, Bubb NL, Wood DJ. Investigation of a hydrophilic primer for orthodontic bonding: an in vitro study. J Orthod. 2000; 27:181-186.

13- Gordan W. Acidic Primers in Dentin and Enamel-Shear Bond Strength and Microleakage [master's thesis]. Iowa City, la; University of Iowa; 1997.

14- Cacciafesta V, Subenberger, U, Jost-Brinkmann, P, Miethke, R. Shear bond strengths of ceramic brackets bonded with different light-cured glass ionorner cements: an in vitro study. Eur J Orthod 1998:20:177-187.

15- Rajapodal R, Padmanabhan S, Gnanamani J. A comparison of shear bond strength and debonding characteristics of conventional, moisture-insensitive, and self-etching primers in vitro. Angle Orthod. 2004; 74:264-268.

16- Bishara SE, Gordan W, VonWald L, Olson ME. Effect of an acidic primer on shear bond strength of orthodontic brackets. Am J Orthod Dentofacial 1998;114:243-247.

17- Cacciafesta V, Sfondrini MF, Angelis MD, Scribante A, Klersy C. Effect of water and saliva contamination on shear bond strength of brackets bonded with conventional, hydrophilic, and self-etching primers. Am J Orthod Dentofacial Orthop 2003; 123:633-640.

18- Grubisa HS, Heo G, Raboud D, Glover KE, Major PW. An evaluation and comparison of orthodontic bracket bond strengths achieved with self-etching primer. Am J Orthod Dentofacial Orthop. 2004; 126:213-219.

19- Grandhi RK, Combe EC, Speidel TM. Shear bond strength of stainless steel orthodontic brackets with a moistureinsensitiveprimer. Am J Orthod Dentofacial Orthop 2001;119:251-5.

20- Zeppieri IL, Chung C-H, Mante FK. Effect of saliva on shear bond strength of an orthodontic adhesive used with moisture-insensitive and self-etching primers. Am J Orthod Dentofacial Orthop. 2003; 124:414-419.

21- Bishata SE, Olsen, ME, Von Wald, L. Evaluation of debonding characteristics of anew collapsible ceramic brackets. Am J Orthod Dentofac Orthop 1997;112:552-559. 